\title{
Lumbar Spine Injuries: Primary Prevention in Amateur and Professional Golf Players
}

\section{(c) (1) (우 $\Theta$}

\author{
Authors \\ Dietmar Goebel ${ }^{1}$, Frank Drollinger ${ }^{2}$, Andrea Drollinger ${ }^{2}$
}

\author{
Affiliations \\ 1 Private Clinic, Orthopaedic Surgery, Donaueschingen, \\ Germany \\ 2 Golf Biomechanic Academy, Teaching, Pforzheim, \\ Germany
}

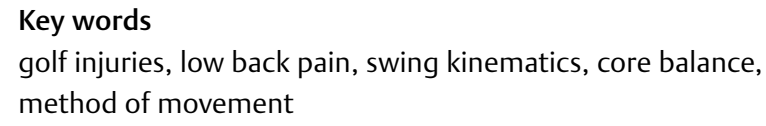

\section{Bibliography}

DOI https://doi.org/10.1055/a-0748-5443

Sports Medicine International Open 2018; 2: E179-E184

(c) Georg Thieme Verlag KG Stuttgart · New York

ISSN 2367-1890

\section{Correspondence}

Dr. Dietmar Goebel

Consultant Orthopaedic Surgeon

Private Clinic

Orthopaedic Surgery

Karlstr. 10

78166 Donaueschingen

Germany

Tel.: +49/771/8986 211, Fax: +49/771/8986 222

goebel-dr-dietmar@t-online.de

\begin{abstract}
In the sport of golf, there is no standard teaching method or swing technique even though golf is known for overuse injuries. This prospective study was to analyze classic swing kinematics in comparison with the Free-Release ${ }^{\circledR}$ method and to define a physiological golf swing. Two hundred eighty-three players, age 50-59 years, were included in the study. For both swing techniques, examination addressed swing visualization, center of pressure (COP), center of mass (COM), as well as pelvic movement in relationship to different standing widths. The position of the spine was evaluated in the frontal and lateral planes. Using the classic technique, no golfer was able to describe his swing parameters, which would be necessary for visualization and to tolerate physiological range of movement, whereas players using the Free-Release method ${ }^{\circledR}$ were able to provide such a description. COP and COM showed pathological swing mechanics for the classic technique, whereas for the Free-Release method mechanics were physiological. We conclude that to prevent lumbar spine injury, the classic swinging technique, which is characterized by lateral shear forces, static and dynamic pelvic side bending while rotating with high force against the spine, and an unbalanced COM and COP, should be substituted by the Free-Release technique as a new physiological guideline.
\end{abstract}

\section{Introduction}

In golf, low back pain is a well known problem described in medical literature as well as non-medical media $[6,10]$. Recent studies even showed that 80 to $100 \%$ of golf players experience spine problems during their career and that around 55 million golf players are affected [5, 6, 17]. Recurrent injuries are frequently seen [24, 33].

Improved swing technique and physical fitness [6] seem to reduce injury frequency. However, even in professional golfers the most com- mon injury site is the back [23]. Recent reports emphasize the importance of physical fitness and proper golf swing techniques but do not specify a swing technique $[1,2,12,18,28]$. There is no definition of a physiological golf swing method in the available literature that can be cited as an injury-preventing guideline. Therefore, this study was to analyze classic golf swing kinematics in comparison to the Free-Release ${ }^{\circledR}$ method (also called the CORE BALANCE Free-Release method) and to define a physiological golf swing for amateur and professional golf players that respects the anatomical range of the lumbar spine. 


\section{Methods}

Of all golfers who contacted the two authors, who are also golf coaches, regarding the Free-Release method between the years 2006 and 2016, we included in this study 283 players, aged 50-59, without any exceptions or exclusion criteria. Because all players contacted the golf coaches of their own volition to improve their playing technique, and because it is standard in every sport to analyze and document the status quo before and after every change in movement technique patterns, no statement of approval by ethics agencies was required. In addition, the first author was blinded to individual results and unable to obtain any personal information about the athletes.

The purpose was to assemble a realistic group of golfers for comparison with the largest age group of American golfers. Players included all performing levels and came from England, Germany, Spain, Switzerland and the United States of America.

All golfers had to answer a questionnaire regarding their biomechanical knowledge of the golf swing, provide an exact description of their swing parameters if possible, as well as their history of low back pain problems and use of analgesics.

Afterwards, all golfers were evaluated on the driving range regarding their swing parameters. For both swing techniques, examination included individual golf swing visualization, the center-ofpressure (COP) and center-of-mass (COM) parameters, as well as pelvic movement in relationship to different standing widths. The position of the spine was evaluated in the frontal and lateral planes during set-up posture.

Frontal and lateral views were documented by a Casio EX-F1 high-speed camera and radar. Analyses afterwards were performed using the Swing At'em Golf app (PEKO Enterprise LLC), the Hudl Technique Golf app, Version 5.3.0 (Hudl, Lincoln, NE, USA), and FlightScope Software Version FS 2.4 (2009) to Version FS X2 10.0. (2015) (FlightScope, Orlando, FL USA).

These analyses were performed for every golfer regarding their existing, classic golf swing and again after a three-day training course using the Free-Release method [3]. The pelvis-spine angle for both methods was documented. Body weight balance on both feet was analyzed during set-up, and COP and COM in the lateral and oblique views were documented at the end of the backswing and during the downswing.

As an additional population, 100 patients between 50 and 70 years of age who consulted a department of physiotherapy for conservative treatment of low back pain after being seen by an orthopedic surgeon were analyzed regarding internal rotation of the hip joint in the straight leg position. The sole exclusion criterion was no previous problem with their hip joints, The group was recruited continuously between September 19, 2017, and November 28, 2017. According to the Ethics Commission of the Baden Wuerttemberg Medical Association in Stuttgart, Germany, special permission was unnecessary, because this criterion has to be documented for every patient prior to treatment in a physiotherapy department in Germany. Therefore, this was not an additional or invasive examination, and the authors of the study had no personal information about the patients themselves nor were able to name or recognize the patients anywhere else [14].

Because a description of the results in percentages was not sufficient, a t-test for recurrent measurement of one group was used.

\section{Results}

None of the golfers in this study who played using the classic technique were able to describe their swing kinematics or name the swing method they used. They could not define any spine or pelvic position during set-up or their backswing or downswing, regardless of their playing level, number of years in the sport or number of lessons taken.

They never had any written swing description and were unable to perform their own mental training because they were unable to visualize a standardized swinging movement/pattern.

Due to their inability to visualize and define their golf swing, they also were unable to tolerate physiological range of movement parameters of the spine. After learning the Free-Release method, all players had a detailed understanding of their swing parameters and their individual spine limitations.

One hundred percent of the players shifted their body weight laterally, showed side bending of the spine, experienced unnecessary shear forces and showed pelvic imbalance during the backand downswing. Pelvic rotation was decreased by a broader standing position ( Fig. 1).

Pelvic imbalance could be avoided in more than 80 percent of players after learning and using the Free-Release method.

The pelvic-spine angle in the classic technique was between $25^{\circ}$ and $32^{\circ}$, which led to additional bending of the cervical spine to be able to see the ball during set-up positioning. This additional cervical spine flexion could be reduced by using the Free-release method.

By analyzing the movement patterns of the COP and COM, a continuous pelvic imbalance ( $\boldsymbol{\text { Fig. }} \mathbf{2}$ ) followed by pelvic tilting was evident during the classic swing technique. The movement pattern was an oblique "eight". During the back- and downswing, COP and COM showed lateral and oblique movement.

Pelvic tilting and instability of the COP were avoided by all players after 3 days of training and using the Free-release method (> Fig. 3).

Internal rotation ability of the hip in the additional population of patients between 50 and 70 years of age (mean age 59 years) showed a mean range of motion in the straight-leg position of $39^{\circ}$ ( $\triangleright$ Fig. 4).

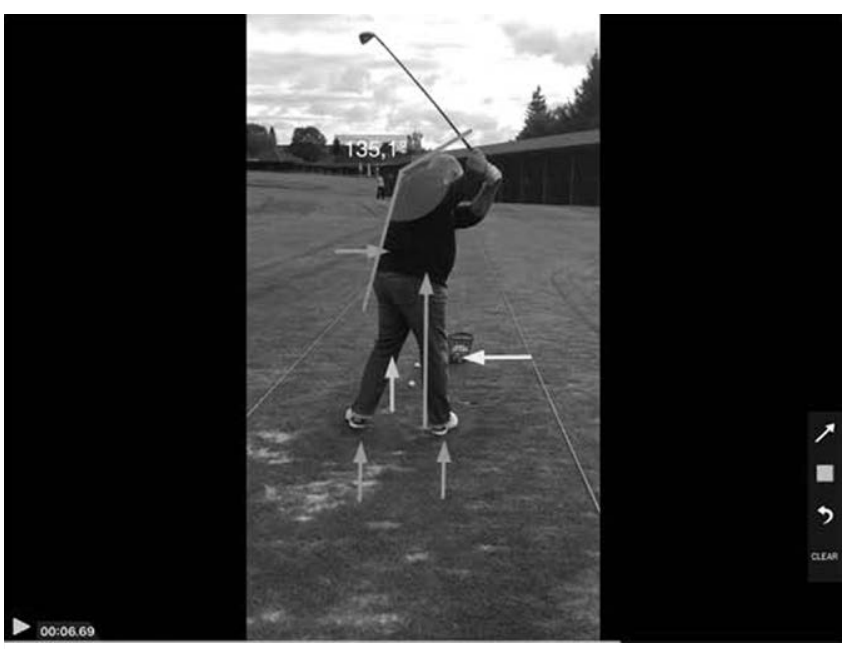

Fig. 1 Athlete using classic technique, with body weight shifted laterally, broad standing position, valgus stress of the front knee during upswing and pathological angle of thoracic to cervical spine. 


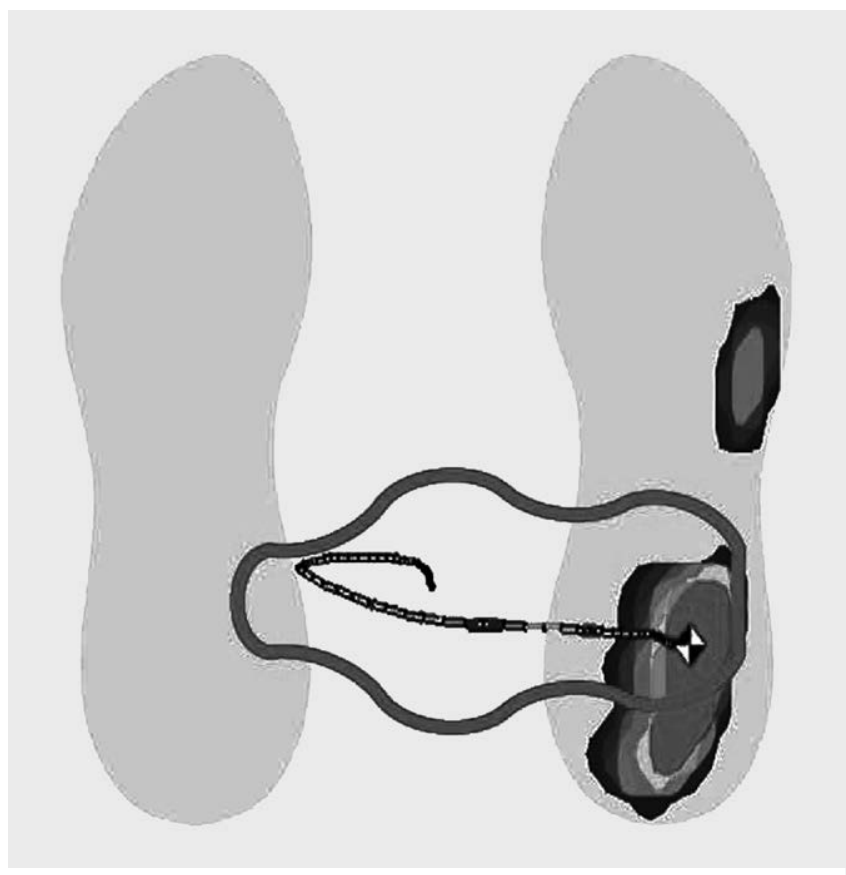

- Fig. 2 COM und COP showing instability in an athlete using classic technique.

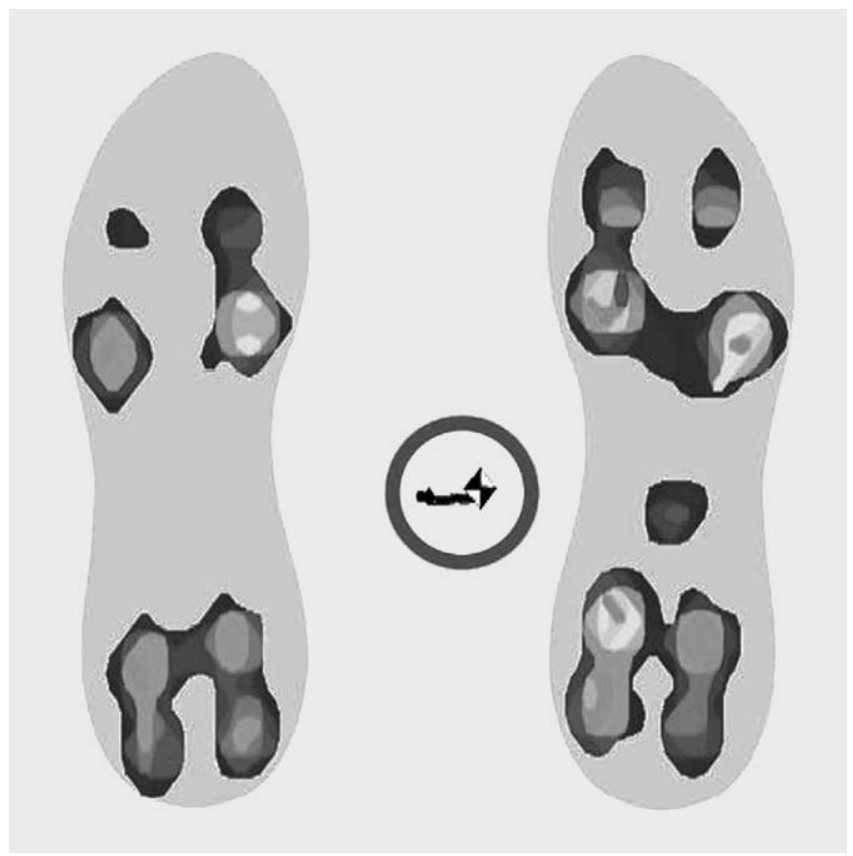

- Fig. 3 Stable COM und COP in an athlete using Free-Release technique.

\section{Discussion}

In recent years, golf has become one of the most frequently practiced sports worldwide and has garnered increased interest with its inclusion in the Olympics in 2016.

Mild cardiovascular exercise and positive effects on pulmonary function as well as metabolic balance cause golf to be recommended by sport physicians for any age group of patients. It is also rec-

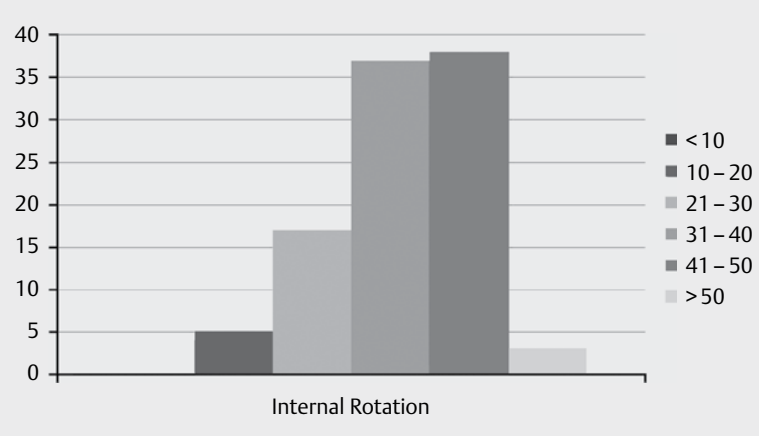

- Fig. 4 Ability of internal rotation of the hip joint in straight leg position in 50 - to 70 -year-old persons $(n=100)$ with no history of hip problems .

ommended to prevent the diseases of civilization brought about by a lack of physical activity $[1,22]$.

However, specific orthopedic problems, especially of the lumbar spine, are well known [5, 12]. According to Haemel, the golfspecific movement procedures (especially the ones related to spinal rotation), combined with pre-existing improper postures, are the main causes for spinal injuries. As in other publications, physiotherapeutic measures und physical therapy are recommended but no detailed analyses of the golf swing parameters along with detailed descriptions and recommendations are given $[12,28]$. The spine problems of professional players like Tiger Woods are well known and described in the public media $[4,7,19,30]$.

Excessive lordosis in combination with spinal rotation is known to cause problems like spondylolysis, spondylolisthesis or scolioses in other sports like gymnastics, ballet dancing, etc. [6, 34]. This is not only basic orthopedic knowledge [34] but also described in patient advice books [10]. However, even in the local media, athletes, orthopedic surgeons, sports physicians and physiotherapists can regularly see pictures of young individual athletes and teams, who are under the continuous guidance of golf coaches during multiple training sessions per week, in positions of forced side bending and spinal rotation, even for short-distance shots, e. g., bunker swings [25].

In light of improper postures of e. g. the pelvis, degenerative changes of the spinal facet joints, lack of muscular stability, and lack of physical training in daily job routines, this study was designed to analyze the age group of golf athletes between 50 and 59 years of age, which is the largest age group of active golfers in the United States [35].

It was shown that players at all levels were unable to describe their swing or set-up parameters. This was true for the back- as well as the downswing. Hence none of the players were able to employ mental training, even though some authors maintain that success in playing golf is based $90 \%$ on mental factors [12]. But how can players visualize and "feel" a swing technique if they are unable to describe it?

Furthermore, if swing technique cannot be described, how can the natural limitations in spinal range of motion be taken into account? Only by respecting these natural limitations can a physiological golf swing method be developed and prevent primary injury. 
These limitations should be specifically noted. The natural range of motion of the lumbar spine is $5-8^{\circ}$ rotation, whereas the hip joint allows an internal/external rotation of $40-50 / 30-40^{\circ}$ (straight leg).

The knee joint allows only minimal rotation but not in the straight position. Moving the knee joint from flexion to extension even leads to a final external rotation, which works against the relatively internal rotation of the front leg $[11,27,31]$.

The ankle is unable to support any type of rotation, which is especially true in the typical slight dorsi-flexed position, in which the broader frontal talus part is pressed between the tibia and fibula. It is therefore surprising that one case study even suggests mobilization of the ankle in dorsi-flexion to reduce the strain on the lumbar spine [28], although there appears to be no anatomical reason for this.

Adding up these ranges of movement in a perfectly healthy young athlete, the result is $58^{\circ}$ of rotation from the ankle to the lumbar spine for each direction of the swing, starting at the set- up position to the end of the backswing or the finish position after the downswing and impact. These limitations are further reduced in the case of hip rotation, as we showed in our population of patients with low back pain in the 50 - to 70 -year-old age group. Their mean internal rotation was $39^{\circ}$ and not as high as the $50^{\circ}$ possible in young athletes. These limitations are based on normal age-related degenerative changes resulting in ventro-lateral impingement, but also in shortening of the external rotator muscles, the latter problem which is solve able through physiotherapy. It is important to note that no patient in this population had any history of hip joint disease. Additional pre-existing problems such as excessive lumbar lordosis, muscle imbalance, etc. may further reduce the abovecited maximal movement values.

These problems associated with the reduced range of motion of the pelvis and hip joint that place higher forces on the lumbar spine are already well described [8, 9, 17, 20, 26, 32]. Publications $[3,8,9]$ describe that changes in foot position during set-up from the sagittal plane, for example, to external rotation of the feet resulting in external rotation of the hips, do not lead to increased rotation of the joint or that a greater than "hip-joint wide" standing position leads to a higher range of spine motion. In reality, it is quite the opposite $[15,17,20,26]$.

These changes lead to instable pelvic movements and higher shear forces as well as decreased range of motion in hip rotation. In basic orthopedic knowledge, a broader standing position leads to ab- and adduction of the hip joint, resulting in decreased internal and external rotation.

During the complete golf swing, the pelvis and lumbar facet joint axis rotate at least $90^{\circ}$ from set-up to the finish position, resulting in a definite overstrain of the locomotor apparatus. Without protective gear - in this case a Turning Shoe that allows $32^{\circ}$ of rotation of the front foot ( $\vee$ Fig. 5,6 ) to add to the $58^{\circ}$ of physiological rotation for the necessary $90^{\circ}$ - a trick move would be needed like the one seen in videos of Tiger Woods jumping after impact to release the tension of the front leg, knee joint and the spine.

It should be noted that shifting the body and center of mass during the backswing - and consequently during the downswing leads to bending of the lumbar spine and the well known consequence of blockage of the facet joints oriented in the sagittal plane of this spinal region $[21,29]$. Independent of clinical experience

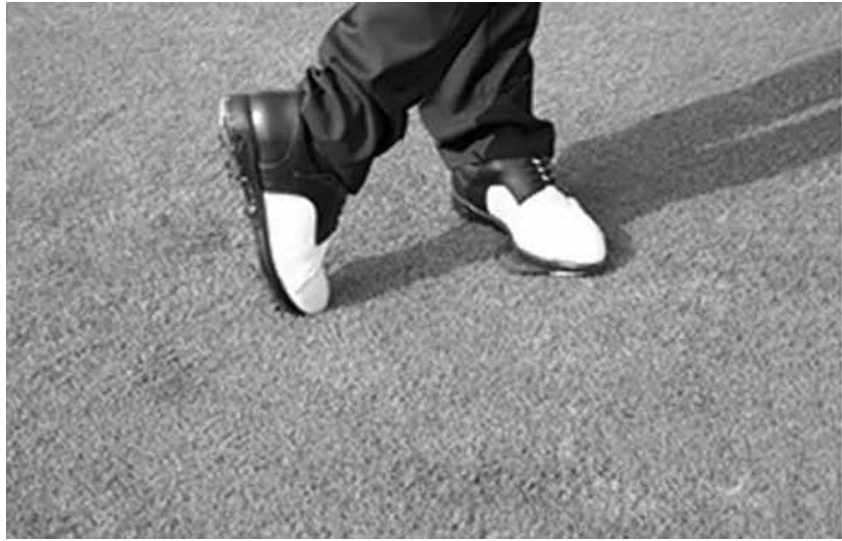

Fig. 5 Turning Shoe at end of golf swing in an athlete using FreeRelease method.

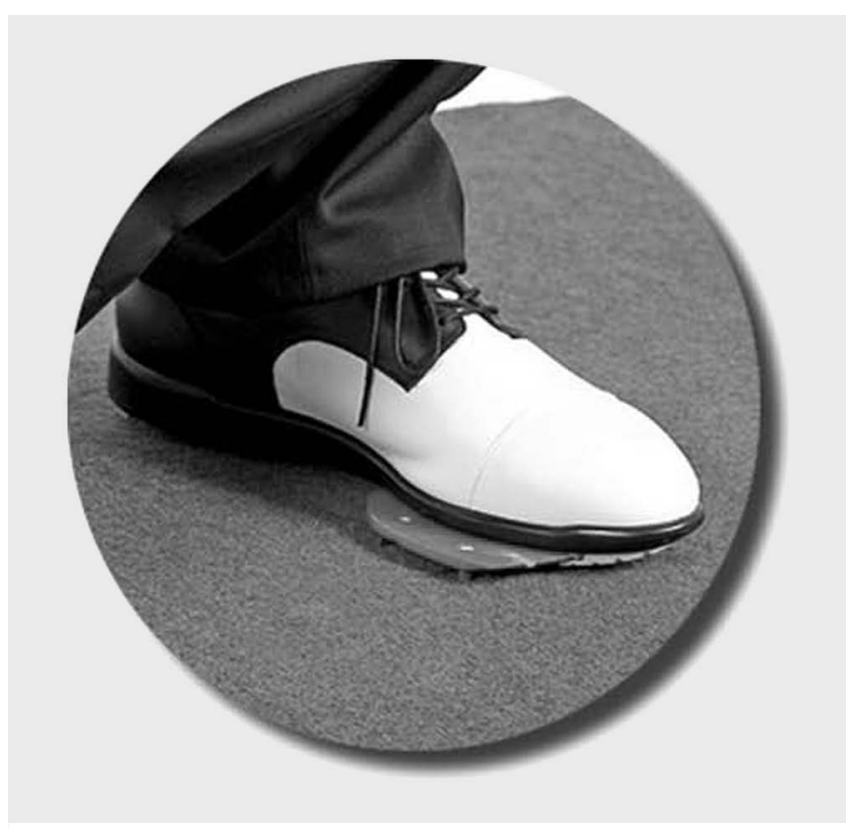

-Fig. 6 Turning Shoe showing released sole to shoe of $32^{\circ}$ degrees, resulting in stress reduction in ankle, knee, hip and spine joints.

and assessment of movement patterns, Heuberer showed that these forces are pathological [15]. This is in agreement with other authors $[1,17,24,33]$.

Therefore, even minimal degrees of lumbar-spine side bending have to be avoided. Consequently, the COM and COP of the body during the golf swing have to be stable. This necessitates body core fitness and a stable longitudinal axis of the spine during the swing.

The classic swing technique, commonly called the Ben Hogan method, is known to be possibly joint damaging $[1,13,16]$. When the classic method, along with a number of variants, is compared with the Free-Release method, only the latter showed stable COM and COP. All golfers, independent of playing level, showed this instability prior to 3 days of learning the Free-Release method.

No golfer was previously able to adhere to the normal limitations of lumbar spine mobility. Hence every golf swing using the 
classic Ben Hogan method could result in a minimal injury leading to more serious acute or overuse injuries as the total number of strokes increases. Using the Free-Release method, all golfers had an exact idea of their swing parameters and were able to visualize the correct swing technique. They were able to tolerate the normal physiological limitations of the lumbar spine and showed a stable COM and COP.

Our study showed that all 283 golfers in the largest age group of athletes in the United States had no concept of their swing parameters and therefore could not visualize them. All primarily used the classic Ben Hogan method or variations thereof and were ignorant of the well known physiological range of spinal movement parameters, possibly leading to acute and overuse injuries. This was already true for the theoretically accepted maximum range of movement in young and healthy athletes and does not consider the added limitations from degenerative changes of the hip and facet joints or any muscle imbalance in the older age group.

COM and COP were instable using the classic method.

After golfers learned the Free-release method, COM and COP were stable, and range of movement of the spine and pelvis was within normal limits, especially when reasonable protective gear like the Turning Shoe ${ }^{\circledR}$ was worn. We therefore recommend a combination of the Free-Release method and the Turning Shoe as a guideline for a healthy golf swing.

However, because every athlete has individual limitations of joint movement in the ankle, knee, hip and spine, especially in the age group with frequent degenerative joint changes and muscle imbalance, we strongly advise additional primary and regular checkups by doctors of sports medicine and physiotherapists in cooperation with the golf coach, all of whom should be experienced in the Free-Release method. This team would able to do the individual fine-tuning of the above technique. Only via this approach can the golf swing technique and sport be considered physiologically sound and healthy overall for the locomotor apparatus.

What is known about the subject: In golf - in both amateur and professional athletes - it is known and more or less accepted that low back pain and overuse injuries of the lumbar spine are quite frequent. (Tiger Woods is the most famous example.) Nonetheless, there is no description of a physiological golf swing method that respects the physiological limitations regarding the range of motion of the lumbar spine. Even in societies like the PGA, there is no uniform healthy swinging technique to teach from the beginner to the professional level in the sport, even though every other type of complex sport, like downhill skiing, has a gold standard.

What this study adds to the existing knowledge; For the first time it can be proven that a healthy golf swing is possible and that overuse injuries of the lumbar spine are completely unnecessary. Therefore, this study is major step forward in injury prevention in sports medicine and can lead to many changes and much discussion in the sport of golf.

\section{Conflict of Interest}

The authors declare that they have no conflict of interest

\section{References}

[1] Boldt F, Ferrauti A, Wolff R. Sportmedizinische Aspekte des Golfsports. Deut Zeit f Sportmed 2000; 51: 67-70

[2] Dalton E.Golf and low back pain. Retrieved from http://erikdalton.com

[3] Drollinger F. Golf - Das neue Testament. Birkenfeld: Novus Plus Verlagsgesellschaft; 2013

[4] Felden O.Grund zur Sorge für Tiger Woods. Retrieved from www. golfpost.de/tiger-woods-ruecken-medizin-7777158197

[5] Fischer S. Biomechanische Belastungsaspekte der Wirbelsäule beim Golfschwung. Sport Orthop Traumatol 2013; 29: 89-95

[6] Garrido E.Golf injuries review. 2014. Retrieved from www.sportsinjurybulletin.com/archives/golf-injury.html

[7] Gessner D. Tiger Woods vor dem bitteren Ende. Sport Bild 2016; 14: 96-97

[8] Goebel D, Drollinger F. Der Golferellenbogen: Überlastung durch Technikfehler? Zeitschrift $f$ Physiotherapie 2016; 68: 59-64

[9] Goebel D, Drollinger A, Drollinger F. Stress reduction of the spine in golf sport. Movement patterns based on physiologic anatomical and biomechanical principles of injury prevention. OUP 2017; 2: 100-107

[10] Grifka J. Der große Ratgeber gesunder Rücken. München: Zuckschwerdt Verlag; 2014

[11] Haaker R, Ortheses.In: Engelhardt M, Dorr A. (eds.) Sports Orthopedics. Edition Medizin. Berlin: Neunplus1; 2011: 769-780

[12] Haemel D, Golf.In: Engelhardt M, Dorr A. (eds.) Sports Orthopedics. Edition Medizin. Berlin: Neunplus 1; 2011: 653-657

[13] Hansra KK. Assessment of stresses in the cervical spine caused by posture and position of the head. Surg Technol Int 2014; 25: 1-3

[14] Harriss DJ, Macsween A, Atkinson G. Standards for ethics in sports and exercise science research: 2018 update. Int J Sports Med 2017; 38: $1126-1131$

[15] Heuberer I. Expertise zum Thema: Lateralverschiebung des Beckens und Rotation der Wirbelsäule beim Golfen. 2015;

[16] Hogan B. Ben Hogan's Five Lessons. The Modern Fundamentals of Golf. New York: Simon and Schuster; 2006

[17] Kim SB, You MSJH, Kwon OY, Yi CH. Lumbopelvic kinematic characteristics of golfers with limited hip rotation. Am J Sports Med 2015; 43: 113-120

[18] Lauterburg M. Der Golfschwung der ihren Rücken schont. Drive 2003; 54-55

[19] Lawrenson D. Tiger admits back pain has him fearing future ahead of Doral return. Mail Online, 5 March 2014

[20] Lejkowski PM, Poulsen E. Elimination of intermittent chronic low back pain in a recreational golfer following improvement of hip range of motion impairments. J Bodyw Mov Ther 2013; 17: 448-452

[21] Lewit K. Manuelle Medizin. 6. AuflLeipzig, Heidelberg: J Ambrosius Barth Verlag; 1992

[22] Walker Research Group. The health \& wellness benefits of golf participation \& involvement. Review of academic literature. Golf 20/20 \& World Golf Foundation, 2011

[23] McCarrol JR. The frequency of golf injuries. Clin Sports Med 1996; 15: $1-7$

[24] McHardy A, Pollard H, Luo K. One-year follow-up study on golf injuries in Australian amateur golfers. Am J Sports Med 2007; 35: 1354-1360

[25] Mueller J. Sein Schwung begeistert Golfprofi. Suedkurier 9 June 2017

[26] Murray E, Birley E, Twycross-Lewis R, Morrissey D. The relationship between hip rotation range of movement and low back pain prevalence in amateur golfers: An observational study. Phys Ther Sport 2009; 10: 131-135 
[27] Netter FH. Farbatlanten der Medizin. The Ciba Collection of Medical Illustrations. Bewegungsapparat 1. Stuttgart-New York: Thieme Verlag; 1992

[28] Randall N.Jonas Blixt case study. From back pain to PGA tour win. Retrieved from www.golfwtx.com/447782/jonas-blixt-case-studyfrom-back-pain-to-pga-tour-win

[29] Sachse J, Schildt-Rudloff K. Manuelle Untersuchung und Mobilisationsbehandlung der Wirbelsäule. Berlin: Ullstein Mosby Verlag; 1992

[30] Siemens J. In der falschen Richtung. Stern, 8 June 2017; 99-100

[31] Sisk D. Knee Injuries. In Crenshaw AH. (ed.) Campbell's Operative Orthopedics. 8th ed. St. Louis: Mosby Year Book; Volume 3 1487-1504
[32] Vad VB, Bhat AL, Basrai D, Gebeh A, Aspergreen D, Andrews JR. Low back pain in professional golfers. Am J Sports Med 2004; 32: 494-497

[33] Wadsworth L, Tyler MD. When golf hurts: Musculoskeletal problems common to golfers. Curr Sports Med Rep 2007; 6: 362-365

[34] Wirth C], Mutschler W. Praxis der Orthopädie und Unfallchirurgie. Stuttgart-New York: Thieme Verlag; 2009

[35] www.statista.com. Share of golf players in the United States by age groups 